University of South Florida

DIGITAL COMMONS

Digital Commons @ University of

@ UNIVERSITY OF SOUTH FLORIDA

South Florida

Rehabilitation and Mental Health Counseling

Faculty Publications

Rehabilitation and Mental Health Counseling

2010

\title{
Real-Time Locating Systems (RTLS) to Improve Fall Detection
}

\author{
Mary E. Bowen \\ James A. Haley Veterans Hospital \\ Jeffrey Craighead \\ James A. Haley Veterans Hospital \\ Chadwick A. Wingrave \\ University of South Florida \\ William D. Kearns \\ University of South Florida, kearns@usf.edu
}

Follow this and additional works at: https://digitalcommons.usf.edu/mhs_facpub

\section{Scholar Commons Citation}

Bowen, Mary E.; Craighead, Jeffrey; Wingrave, Chadwick A.; and Kearns, William D., "Real-Time Locating Systems (RTLS) to Improve Fall Detection" (2010). Rehabilitation and Mental Health Counseling Faculty Publications. 103.

https://digitalcommons.usf.edu/mhs_facpub/103

This Article is brought to you for free and open access by the Rehabilitation and Mental Health Counseling at Digital Commons @ University of South Florida. It has been accepted for inclusion in Rehabilitation and Mental Health Counseling Faculty Publications by an authorized administrator of Digital Commons @ University of South Florida. For more information, please contact digitalcommons@usf.edu. 


\title{
Original research
}

\section{Real-Time Locating Systems (RTLS) to improve fall detection}

\author{
Mary Elizabeth Bowen PhD \\ James A. Haley Veterans Hospital, \\ HSR\&D/RR\&D Center of Excellence \\ 8900 Grand Oak Circle, Tampa, FL 33637, USA \\ E: mary.bowen3@va.gov \\ Jeffrey Craighead PhD \\ James A. Haley Veterans Hospital, \\ HSR\&D/RR\&D Center of Excellence, Tampa, FL, USA
}

\author{
Chadwick A. Wingrave PhD
}

Department of Electrical Engineering and Computer Science, University of Central Florida, Orlando, FL, USA

\section{William D. Kearns PhD}

Department of Aging and Mental Health Disparities, University of South Florida, Tampa, FL, USA

\begin{abstract}
M.E. Bowen, J. Craighead, C.A. Wingrave, W.D. Kearns. Real-Time Locating Systems (RTLS) to improve fall detection. Gerontechnology 2010; 9(4):464-471 doi:10.4017/gt.2010.09.04.005.00 Objective To determine whether a Real Time Locating System (RTLS) can be used to accurately detect a fall and discuss the application of RTLS as a fall detection system in the home and health care environments. Methods Phase I used a mannequin to determine the feasibility of RTLS to detect a fall from three positional conditions of: standing, seated in a wheelchair, and laying on a bed. Phase II used a human subject to be an ecologically valid simulation of a fall from these conditions. Ten trials of each of these three conditions were conducted across subjects. The observed time of the fall (the 'gold standard') was compared with the RTLS tag position. A Receiver Operating Characteristic (ROC) curve was used to report the Area Under the Curve (AUC) with 95\% confidence intervals $(\mathrm{Cl})$ and Cohen's kappa $(\boldsymbol{x})$ was used to examine inter-rater reliability between the observed fall and the fall detected by the RTLS. Results RTLS accurately identified $89 \%$ ( $p \leq 0.001)$ of the mannequin falls and $80 \%$ $(p \leq 0.001)$ of the human falls. Across subjects there were low false positive rates (specificity); $17 \%$ for the mannequin and $16 \%$ for the human. Interrater reliability was very good $(\boldsymbol{\varkappa}=0.82 ; \mathrm{Cl}$ : $0.80-0.84)$ for mannequin falls and good $(\boldsymbol{\varkappa}=0.72 ; \mathrm{Cl}$ : 0.69-0.74) for human falls. Implications RTLS technology may be used to improve caregiver and staff response times, patient-care, and reduce health care costs associated with falls in later life.
\end{abstract}

Keywords: health care, elderly, radio-frequency identification devices (RFID)

Elderly falls are a serious global problem. For example, one third of Americans aged 65 and older fall each year ${ }^{1}$ with 30 percent of these resulting in moderate to severe injuries, including hip fractures and traumatic brain injury ${ }^{2}$. Falls, and fall-related injuries, are associated with an increased use of health care services and high health care costs. The average fall-related hospital admission rate among older adults in the United Kingdom is 169 per 10,000 population ${ }^{3}$; in British Columbia, Canada, this rate is $\mathbf{1 5 5}$ per 10,000 population $^{4}$; and in Western Australia this rate is 297 per 10,000 popula- 
tion $^{5}$. The average length of hospital stay for an older adult who falls is $4-15$ days ${ }^{4-9}$. This average increases to 20 days with an injurious fall (for instance, hip fracture) ${ }^{10}$. Among adults aged 65 and older in the United States and Canada, fall-related injuries account for $6-7 \%$ of all hospitalizations and more than $50 \%$ of all hospitalizations due to accidental injuries ${ }^{4,6}$. In Finland and Australia, the average cost per fall among adults aged 65 and older ranges from US\$1,050-\$3,600 11-12. The average cost for an injurious fall ranges from US\$6,500-7,500 ${ }^{6}, 13$, with injurious falls accounting for 70 percent of total inpatient costs ${ }^{13}$. In 2000, total direct costs for fall injuries among older Americans exceeded $\$ 19$ billion $^{14}$.

Fall risks include muscle weakness or gait problems, visual impairment, dementia or cognitive impairment, medical conditions, and use of sedatives ${ }^{15}$. Long-term care residents are two times more likely than their community-dwelling counterparts to fall and falls are the most commonly reported adverse event in long-term care facilities ${ }^{15}$. In nursing facilities, fall risk is increased during periods of low supervision -- when staffing is low due to breaks and shift changes ${ }^{16}$. For example, many falls occur during unsupervised transfers in and out of a wheelchair or bed ${ }^{17}$. For a 100-bed facility, fall estimates range from 100-200 falls/year $^{18}$. In the Veterans Health Administration (VHA), the fall rate is about $10 \%{ }^{19-20}$. Due to under-reporting, these statistics may actually underestimate fall incidence ${ }^{18}$. The aim of this study is to determine the feasibility of a real-time locating system (RTLS), a tracking technology, to detect falls and discuss how this technology may improve patient care and effectively reduce fall-related health care costs.

\section{A REVIEW OF TRACKING TECHNOLOGIES}

A variety of low- and high-tech tools have been employed to both reduce the rate of injurious falls and alert caregivers, staff, and emergency responders to a fall. Examples include grab bars, raised toilet seats, low beds, handrails in hallways, and other envi- ronmental changes to promote safe transfers and ambulation in home and nursing facilities ${ }^{17}$. Recent work shows that hip protectors significantly reduce injurious fall risk ${ }^{21}$ whereas previous tools such as wheelchair and bed restraints may actually increase fall risk and death and are no longer recommended $^{22}$.To evaluate balance, gait, and subsequent fall risk, wireless sensors installed in carpets, clothing, and rooms can be installed in the home ${ }^{23}$. Other devices, such as video monitoring systems are in development to alert caregivers and staff to a fall and to determine the type of assistance required $^{24-25}$. However, some of these video monitoring systems can be invasive as they identify older adults and record their movements over time. Computer vision can be cheap with commodity cameras but is currently not a robust technology; existing systems are sensitive to changing lighting conditions and often generate false positives, such as when large pets are in view. Medical alert devices such as Lifeline ${ }^{26}$, consisting of a wearable panic button linked to a live operator, may be helpful in home and health care environments. However, older adults with impaired cognition may not be able to use these properly after a fall occurs.

The interactive computer graphics community commonly uses multiple tracking technologies to identify points in space ${ }^{27}$. The technologies use a variety of approaches and vary widely in their performance and limitations. Typically, these devices track in only a small and instrumented area (common tracked areas are about $25.4 \times 25.4 \mathrm{~cm}$ ), have interference problems that must be designed for and are expensive; but, these are fairly accurate and have fast updates. Recent approaches use commodity hardware to approach similar results at lower costs and with less instrumentation, potentially allowing for ubiquitous tracking ${ }^{28}$. Ultimately, the tracking technology chosen is dependent upon the project tasks and tradeoffs in design.

A review of these technologies ${ }^{28}$ demonstrates that historically, there has been no 
technology that fulfills the criteria necessary for monitoring older adults in the home and health care environments. This would require small, wireless, wide-area tracking, with no line of sight issues and good accuracy. A recent tracking technology, the Ubisense ${ }^{29}$ real-time locating system (RTLS) may be an exception. This system is currently used to track asset movement, such as goods in a warehouse. Where previous systems (infrared, visible light, ultrasonic) were blocked by walls or had short ranges (magnetic), the ultra-wideband radio signals used by Ubisense are highly resistant to obstruction and attenuation because of the innate characteristics of the signal. This allows it to better penetrate walls, furniture, and track large areas. As such, one system could potentially cover multiple rooms (in the home or a nursing facility) as opposed to requiring a separate system for each room. Additionally, these systems use compact wireless tags. By embedding these tags in objects such as wristbands, movements of residents in long-term care facilities can be non-invasively monitored, recording their location, time of day, and storing this information for later analysis ${ }^{30}$.

Some health care facilities, including the $\mathrm{VHA}$, are implementing these systems to monitor and track missing or incapacitated patients. Thus, if feasible as a fall detection technology, the Ubisense system may be dual-use, which would significantly reduce implementation costs. Though each site differs, implementing this system in a small home, and assuming some wall penetration, would cost about US $\$ 10,000$ (US $\$ 1,500 /$ sensor, US $\$ 100 / \operatorname{tag})^{31}$. While there is no 'typical' nursing facility (the number of patients and beds vary as does wall penetration - some walls are firewalls and would block the ultra-wideband radio frequency signal) costs to implement this system on one unit or floor (for instance, hallways, activity and eating areas, around the nursing station) would be similar to a small home.

The aim of this study is to use height data to build on existing research and examine whether RTLS may also be used to detect falls. Phase I of this study uses a mannequin to determine whether RTLS may be used to detect falls from three positional conditions of: standing, seated in a wheelchair, and laying on a bed. After feasibility is determined, phase II repeats these tests with a human subject. The observed time of the fall (the 'gold standard') is compared with the RTLS position tags. It was expected that RTLS would accurately detect falls across these three positions and have high inter-rater reliability. If RTLS technology accurately detects falls, this study's findings may be used to improve caregiver and staff response times to a fall, thereby improving patient-care and reducing associated health care costs.

\section{Methodology Setting}

A lab equipped with four active Ubisense ${ }^{29}$ RTLS sensors was used in this study. The Ubisense system was used because it is an existing RTLS technology that was developed for wide area tracking and can track the position of a tag in three dimensions to within $25.4 \mathrm{~cm}$ of its actual position, as defined in reference to a system wide origin point $^{32}$. The Ubisense system is capable of providing location updates at $40 \mathrm{~Hz}$, however, for this experiment an update rate of $4 \mathrm{~Hz}$ was used. In terms of applicability to a health care environment, Ubisense also has low power requirements and multiple tracked points which do not interfere with sensitive medical equipment ${ }^{30}$. A single Ubisense compact tag was placed on the wrist of the human subject and the mannequin during the experiment. Data collection was performed using a Dell laptop computer running Windows XP, Ubisense's Location Engine software version 2.1.4, and a custom application developed by one of the authors (JDC) that recorded the $X, Y, Z$ position of tags into a SQLite database. The Ubisense system that is installed in the lab is only calibrated when the hardware configuration changes. System calibration is a function built in to the Ubisense Location Engine software. For this experiment no cali- 
bration was performed. Lastly, a wheelchair and hospital bed was used to simulate a fall from seated and laying positions. It should be noted that the system calibration is invariant to the height of the object to which a tag is attached.

\section{Subjects}

A mannequin was initially used as a proxy for a human subject to test the feasibility of RTLS to detect falls from three positions (standing, seated in a wheelchair, and laying on a bed). Following determination of proof of concept, the experiment was repeated with a healthy human subject (female, age 30) using a floor mat to prevent injury. The study was approved by the IRB (Integrity of Research Board, a medico-ethical committee) at the University of South Florida in Tampa, FL and the Research and Development Committee at the JAHVH in Tampa, FL, USA.

\section{Data collection instruments}

RTLS compact tags were fitted to the wrist of the mannequin and human subject (Figure 1). Compact tag location was automatically determined with reference to the known sensor locations using Ubisense software.

\section{Data collection protocol}

The accuracy of the RTLS equipment was checked at the start of the study to ensure $x$, $y$, and $z$ coordinates accurately represented

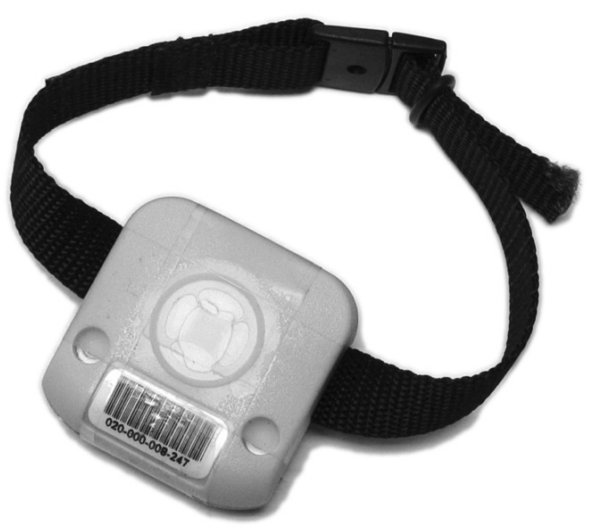

Figure 1. RTLS wristband with compact tag used in this study. It is both small and wireless, making it useful in this domain the relative position of the compact tag in all three dimensions.

In phase I, the mannequin was dropped from a standing position and pushed from a seated position in a wheelchair and a laying position in a bed. Each condition's ten trials, standing first followed by sitting followed by laying, were conducted with the mannequin held in each condition for 5 to 10 seconds before being dropped or pushed. Data were continuously collected across a roughly two hour time period for each subject, with the simulated fall data interspersed in that continuous data stream.

\section{Data reduction and analysis}

Data points generated from tags were plotted to determine the altitude of the compact tags. Analyses were conducted using SAS software version $9.2^{33}$. A Receiver Operating Characteristic (ROC) curve, most often used in medical research to evaluate diagnostic tests, was used to evaluate the ability of RTLS to discriminate between a fall and no fall. ROC curves were used to determine the best cutoff to maximize sensitivity and specificity. ROC curves report the Area Under the Curve (AUC), graphically depicting the true positive rate (sensitivity) by the false positive rate (1-specificity; Figure 2) as its discrimination cutoff is varied with $95 \%$ confidence intervals $(\mathrm{Cl})$. Cutoff points maximized the AUC for each position by subject (Table 1). Cohen's kappa (K) was used to determine inter-rater reliability between the record of the observed fall (the 'golden standard') and the RTLS tag position. This approach represents the simplest classification possible. Algorithms incorporating time and positional change could easily improve recognition. ${ }^{34-35}$

\section{Results \\ Mannequin}

When the mannequin was held upright in a standing position, seated in a wheelchair, or laying on the bed, the compact tag fitted on the mannequin's wrist was about 0.5 meters above the floor. Across all positions, 


\section{Improving fall detection}

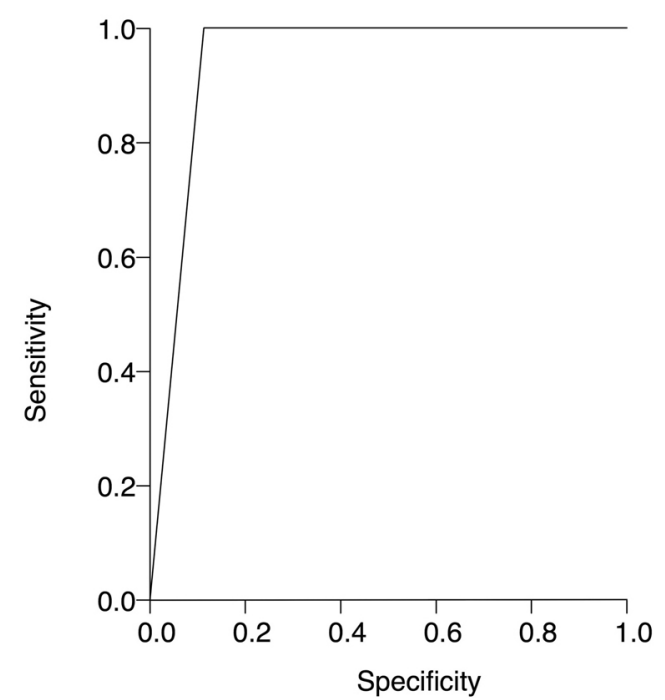

Figure 2. Results from an ROC curve depicting a human fall from a laying position

RTLS accurately identified $89 \%(\mathrm{p} \leq 0.001)$ of the mannequin falls using an overall cutoff value of 0.1 meters (Table 1 ).

In the mannequin falls there was a low false positive rate (specificity). Overall $17 \%$ of cases were identified by RTLS as a fall when there actually was none. There was also very good $(\boldsymbol{\varkappa}=0.82 ; \mathrm{Cl}: 0.80-0.84)$ inter-rater reliability between observed falls and RTLS detected falls.

\section{Human}

With the human subject moving about the lab during the continuous data collection, the compact tag fitted on the human subject's wrist varied between 0.6 and 1.6 meters above the floor. As with the mannequin trials, human testing showed that, across all positions, RTLS positively identified $80 \%$ $(p \leq 0.001)$ of human falls using an overall cutoff value of 0.2 meters (Table 1). For example, as the AUC in the ROC curve (Figure 2) depicts, RTLS had high sensitivity and specificity, significantly detecting $94 \%$ of falls from a laying (bed) position. The AUC for human falls was less than that of the mannequin falls. In the human trials there was a low false positive rate (specificity). Overall, $16 \%$ of cases were identified by RTLS as fall when there actually was none. The higher false positive rate may be due to sensor visibility. The signal from the RTLS tag passes through the mannequin (made of plastic) better than a human (consisting mostly of water). Over the course of the testing, the human moved throughout the lab, bending over, swinging arms, and making other movements to test the movement of the position of the tag in space. These movements had little or no effect on the ability of the RTLS system to detect falls. There was good $(\varkappa=0.72$; Cl: $0.69-0.74)$ inter-rater reliability between the observed falls and RTLS detected falls in human trials.

\section{Discussion}

This study extends the current application of RTLS by examining its feasibility as a fall detection method. Using a mannequin and human subject, RTLS accurately detected a fall from three positional conditions of: standing, seated in a wheelchair, and laying on a bed with high inter-rater reliability. The AUC was high and the false positive rate (specificity)

Table 1. ROC (Receiver Operating Characteristic) curve results across mannequin and human subject trials by position, based on 10 trials of each position per subject; $A \cup C=$ area under the curve; $\mathrm{Cl}=$ confidence interval; Sensitivity=True position rate; Specificity=False positive rate

\begin{tabular}{|c|c|c|c|c|c|c|c|c|}
\hline \multirow{2}{*}{ Position } & \multicolumn{4}{|c|}{ Mannequin } & \multicolumn{4}{|c|}{ Human subject } \\
\hline & $\operatorname{AUC}(\mathrm{CI})$ & Sensitivity & Specificity & Cutoff & $\operatorname{AUC}(\mathrm{CI})$ & Sensitivity & Specificity & Cutoff \\
\hline Standing & $\begin{array}{c}0.86 \\
(0.81-0.92)\end{array}$ & 0.96 & 0.22 & 0.1 & $\begin{array}{c}0.80 \\
(0.67-0.94)\end{array}$ & 0.82 & 0.21 & 0.2 \\
\hline Sitting & $\begin{array}{c}0.90 \\
(0.86-0.93)\end{array}$ & 1.00 & 0.20 & 0.1 & $\begin{array}{c}0.77 \\
(0.66-0.88)\end{array}$ & 0.71 & 0.17 & 0.2 \\
\hline Laying & $\begin{array}{c}0.89 \\
(0.83-0.95)\end{array}$ & 0.91 & 0.13 & 0.2 & $\begin{array}{c}0.95 \\
(0.92-0.98)\end{array}$ & 1.00 & 0.10 & 0.2 \\
\hline Overall & $\begin{array}{c}0.89 \\
(0.85-0.93) \\
\end{array}$ & 0.95 & 0.17 & 0.1 & $\begin{array}{c}0.80 \\
(0.73-0.78) \\
\end{array}$ & 0.77 & 0.16 & 0.2 \\
\hline
\end{tabular}


was low for both the mannequin and human subject trials. There was some evidence that RTLS is better able to distinguish a mannequin fall than a human fall. This is likely because it is more difficult for the sensors to detect the position of the tag through a human subject when compared to a mannequin. The next phase of this research is to examine the ability of RTLS to detect falls in a clinical setting with multiple people over time. Additionally, algorithms such as those used for handwriting recognition and 3D hand gestures will be applied to improve the recognition accuracy ${ }^{34-35}$.

The findings from this study suggest that RTLS may be used to improve fall detection in home and health care environments. When properly integrated with alarm systems, RTLS may be useful to alert caregivers and staff, effectively reducing response time. This is important as an older adult who falls and does not receive prompt medical attention may suffer more severe injury or even death ${ }^{36}$. Additionally, some older adults are afraid of falling ${ }^{37}$ and this fear of falling is associated with decreased mobility and functioning ${ }^{38}$. RTLS may reduce these fears, adding a layer of security for the older adult living alone. In nursing facilities, RTLS has the potential to simultaneously monitor multiple at-risk older adults, covering a wide area. Thus, RTLS may be particularly useful during harried periods of the day and when nursing facilities are short on staff. Lastly, as some falls go unreported, some nursing facilities may also use RTLS to determine fall incidence and monitor changes in fall rates over time.

Several limitations should be considered when interpreting the results of this study. First, we only tested Ubisense equipment. This study used Ubisense equipment because it is an active RTLS system with wide

\section{Acknowledgements}

The authors would like to acknowledge support from the Center of Excellence in Tampa, $\mathrm{FL}$, including the use of the gait and balance lab, materials, mannequin, and RTLS. Dr. Bowen, the corresponding author, is supported by range capability that has been shown to accurately track multiple people over time, characteristics that make this system feasible for use in a health care setting ${ }^{30}$. To our knowledge, there are no other RTLS systems with this capability. However, similar to other systems and devices (for instance, Lifeline), some older adults with cognitive impairment may forget to wear the wristband. This is more likely to be an issue in the home environment as opposed to nursing facilities where staff can better ensure adherence. Second, as this was a feasibility study, this study tested only a mannequin and human subject in the lab. Finally, the human testing in this study consisted of continuous movement around the lab and results suggest that bending and other low positions had little to no effect on the ability of RTLS to accurately detect a fall. However, future work incorporating time and positional change into the algorithm could better address this issue.

Despite these limitations, this study's findings suggest that RTLS is an accurate fall detection method. Given that falls in later life are associated with an increased risk for dependence, institutionalization, and mortality, this study's findings have important implications for older adults and their caregivers living at home and in nursing facilities. In the home, RTLS may effectively reduce caregiver burden and stress, adding a layer of security that effectively reduces the level of vigilance required when taking care of a frail older adult. As an additional safeguard, RTLS may also reduce the older adult's fear of falling. In a nursing facility, RTLS may be used by staff to monitor multiple residents at once over a wide area. When properly integrated into an alarming system, RTLS has additional implications, potentially alerting staff to a fall and ensuring a prompt fall response.

an interdisciplinary fellowship in patient-safety from the Office of Academic Affairs, Veterans Health Administration (VHA). Dr. Craighead is supported by a grant from the VHA, designing smart home living for polytrauma veterans. Dr. Wingrave is supported by an award from the 
National Science Foundation on Concept-Oriented Design and an award from the US Army Research, Development and Engineering Command (RDECOM). Dr. Kearns is supported by an award from the Agency for Health Care Research and Quality (AHRQ;1R21HS018205-01) to evaluate automatic fall prediction systems.

\section{References}

1. Hausdorff JM, Rios DA, Edelberg HK. Gait variability and fall risk in community-living older adults: a 1-year prospective study. Archives of Physical Medicine and Rehabilitation 2001;82(8):1050-1056; doi:10.1053/ apmr.2001.24893

2. Sterling DA, O'Connor JA, Bonadies J. Geriatric falls: injury severity is high and disproportionate to mechanism. Journal of Trauma Injury Infection and Critical Care 2001;50(1):116-119; doi:10.1097/00005373200101000-00021

3. Scuffham P, Chaplin S, Legood R. Incidence and costs of unintentional falls in older people in the United Kingdom. Journal of Epidemiology and Community Health 2003;57(9):740-744; doi:10.1136/ jech.57.9.740

4. Herman M, Gallagher E, Scott V. The evolution of senior's fall prevention in British Columbia. Victoria: Britsh Columbia Ministry of Health; 2006; www.health.gov.bc.ca/ library/publications/year/2006/falls_report. pdf; retrieved September 6, 2010

5. Hendrie D, Hall SE, Arena G, Legge M. Health system costs of falls of older adults in Western Australia. Australian Health Review 2004;28(3):363-373; doi:10.1071/ AH040363

6. Roudsari BS, Ebel BE, Corso PS, Molinari NA, Koepsell TD. The acute medical care costs of fall-related injuries among the U.S. older adults. Injury 2005;36(11):1316-1322; doi:10.1016/j.injury.2005.05.024

7. Seematter-Bagnoud L, Wietlisbach V, Yersin B, Bula CJ. Healthcare utilization of elderly persons hospitalized after a noninjurious fall in a Swiss academic medical center: Noninjurious falls and services use. Journal of the American Geriatric Society 2006;54(6):891-897; doi:10.1111/j.15325415.2006.00743.x

8. Nordell E, Jarnlo GB, Jetsen C, Nordstrom $\mathrm{L}$, Thorngren KG. Accidental falls and related fractures in 65-74 year olds: a retrospective study of 332 patients. Acta Orthopaedica Scandinavica 2000;71(2):175-179; doi:10.1080/000164700317413157

9. Bergeron E, Clement J, Lavoie A, Ratte S, Bamvita J, Aumont F, Clas D. A simple fall in the elderly: not so simple. The Journal of Trauma Injury Infection and Critical
Care 2006;60(2):268-273; doi:10.1097/01. ta.0000197651.00482.c5

10. Parrott S. The economic cost of hip fracture in the UK. York: University of York; 2000 (June); www.viewcare.co.uk/Publications/hipfracture.pdf; retrieved September 6, 2010

11. Hendrie D, Hall SE, Legge M, Arena G. Injury in Western Australia: The health system cost of falls in older adults in Western Australia. Perth: Government of Western Australia; 2003 (November); www.health. wa.gov.au/docreg/Education/Prevention/ Injury_Prevention/HP1695_injury_WA_ health_system_costs_of_falls.pdf; retrieved September 6, 2010

12. Nurmi I, Luthje P. Incidence and costs of falls and fall injuries among elderly in institutional care. Scandinavian Journal of Primary Health Care 2002;20(2):118-122; doi:10.1080/pri.20.2.118.122.

13. Carey D, Laffoy M. Hospitalisations due to falls in older persons. Irish Medical Journal 2005;98(6):179-181

14. Stevens JA, Corso PS, Finkelstein EA, Miller TR. The costs of fatal and non-fatal falls among older adults. Injury Prevention 2006;12(5):290-295; doi:10.1136/ ip.2005.011015

15. Rubenstein LZ, Josephson KR, Robbins AS. Falls in the nursing home. Annals of Internal Medicine 1994;121(6):442-451

16. Gross $Y T$, Shimamoto $Y$, Rose CL, Frank B. Why do they fall? Monitoring risk factors in nursing homes. Journal of Gerontological Nursing 1990;16(6):20-25

17. Ray WA, Taylor JA, Meador KG, Thapa PB, Brown AK, Kajihara HK, Davis C, Gideon P, Griffin MR. A randomized trial of a consultation service to reduce falls in nursing homes. JAMA 1997;278(7):557-562; doi:10.1001/jama.278.7.557

18. Rubenstein LZ. Preventing falls in the nursing home. JAMA 1997;278(7):595-596; doi:10.1001/jama.278.7.595

19. Center VIR. Research findings from the VA Medicare Data Merge Initiative: Veterans' enrollment, access and use of Medicare and VA health services. Hines: Hines Veterans Administration Hospital; 2002

20. Stalhandske E, Mills P, Quigley P, Neily J, Bagian J. VHA's National Falls Collaborative and Prevention Programs: Agency for Healthcare Research and Quality; Ann Arbor: VHA National Center for Patient Safety; 2007; www.ahrq.gov/downloads/ pub/advances2/vol2/Advances-Stalhandske2_70.pdf; retrieved September 6, 2010

21. Nelson A, Powell-Cope G, GavinDreschnack D, Quigley P, Bulat T, Baptiste AS, Applegarth S, Friedman 
Y. Technology to promote safe mobility in the elderly. Nursing Clinics of North America 2004;39(3):649-671; doi:10.1016/j. cnur.2004.05.001

22. Miles SH, Irvine P. Deaths caused by physical restraints. Gerontologist 1992;32(6):762766

23. Junnila $S$, Kailanto $H$, Merilahti J, Vainio A-M, Vehkaoja A, Zakrzewski M, Hyttinen J. Wireless, multi-purpose in-home health monitoring platform: two case trials. IEEE Transaction on Information Technology in Biomedicine 2010;14(2):447-455; doi: 10.1109/TITB.2009.2037615

24. Lee T, Mihailidis A. An intelligent emergency response system: preliminary development and testing of automated fall detection. Journal of Telemedicine and Telecare 2005;11(4):194-198; doi:10.1258/1357633054068946

25. Anderson D, Luke RH, Keller JM, Skubic M, Rantz M, Aud M. Linguistic Summarization of Video for Fall Detection Using Voxel Person and Fuzzy Logic. Computer Vision and Image Understanding 2009;113(1):8089; doi:10.1016/j.cviu.2008.07.006

26. Philips. Lifeline -- the trusted medical alert service provider: Philips; 2004-2010; www. lifelinesys.com/content/home; retrieved September 6, 2010

27. Welch G, Foxlin E. Motion tracking: no silver bullet, but a respectable arsenal. IEEE Computer Graphics and Applications 2002;22(6):24-38; doi:10.1109/ MCG.2002.1046626

28. Wingrave $C A$, Williamson $B$, Varcholik PD, Rose J, Miller A, Charbonneau E, Bott J, LaViola JJ. Wii remote and beyond: using spatially convenient devices for 3DUI's. IEEE Computer Graphics and Applications 2010;30(2):71-85; doi:10.1109/ MCG.2009.109

29. Ubisense. Real-Time Location Fact Sheet. 2009; www.ubisense.net/pdf/fact-sheets/ products/software/Real-time-LocationEN090908.pdf; retrieved September 6, 2010
30. Kearns WD, Nams VO, Fozard JL. Tortuosity in Movement Paths Is Related to Cognitive Impairment. Wireless Fractal Estimation in Assisted Living Facility Residents. Methods of Information in Medicine 2010;49:preprint online; doi:10.3414/ME0901-0079

31. Ubisense. Ubisense products 2009; www. ubisense.net/en/industries; retrieved September 6, 2010

32. Kearns W, Algase D, Moore DH, Ahmed S. Ultra wideband radio: a novel method for measuring wandering in persons with dementia. Gerontechnology 2008;7(1):4857; doi:10.4017/gt.2008.07.01.005.00

33. SAS Institute Inc. SAS® 9.2 Software: Enabling more proactive and effective decision making. Cary: NC SAS Institute; 2010; www.sas.com/software/sas9/; retrieved September 6, 2010

34. Rubine D. Specifying gestures by example. ACM SIGGRAPH Computer Graphics. 1991;25(4):329-337; doi:10.1145/127719.122753

35. Hoffman M, Varcholik P, LaViola J. Breaking the status quo: improving 3D gesture recognition with spatially convenient input devices. Proceedings of IEEE Virtual Reality 2010; pp 59-66; 0.1109/VR.2010.5444813

37. Tzeng HM, Yin CY. Relationship between call light use and response time and inpatient falls in acute care settings. Journal of Clinical Nursing 2009;18(23):3333-3341; doi:10.1111/j.1365-2702.2009.02916.x

38. Vellas BJ, Wayne SJ, Romero LJ, Baumgartner RN, Garry PJ. Fear of falling and restriction of mobility in elderly fallers. Age and Ageing 1997;26(3):189-193; doi:10.1093/ageing/26.3.189

39. Guideline for the prevention of falls in older persons. American Geriatrics Society, British Geriatrics Society, and American Academy of Orthopaedic Surgeons Panel on Falls Prevention. Journal of the American Geriatric Society 2001;49(5):664-672; doi:10.1046/j.1532-5415.2001.49115.x 